\title{
Schmalenbach Business Review Special Issue on \\ International Strategy and Cross-Cultural Management Editorial
}

\section{Why International Strategy and Cross-Cultural Management Matters in Business Research and Education}

The articles in this special issue are based on papers presented at the 8th EIASM (European Institute for Advanced Studies in Management) Workshop on International Strategy and Cross-Cultural Management at Tübingen University from 8 to 9 October 2010. As organizers of this workshop series and guest editors of this special issue, we are grateful to the Schmalenbach Business Review (sbr) for granting us the opportunity to publish selected papers from this workshop. We are appreciative for two reasons in particular: first, because only rarely does sbr publishes special issues, in fact, since 2002 there have been only two; second, because our topic does not fall into one of the areas in which $s b r$ prefers to publish, i.e., accounting, finance, marketing, or organization. It is this second reason that we wish to explore in some more detail.

By covering areas as wide as the ones mentioned above, both Schmalenbachs Zeitschrift für betriebswirtschaftliche Forschung (zfbf), which is the oldest and most prestigious German journal of business studies, and its international edition $s b r$, which began publishing in 2000, clearly stand in the tradition of German business research journals. This fact is also specifically highlighted in the aims and scope section of $s b r$. In contrast, if we look at some U.S.-based general management journals, for example, those published by the Academy of Management - i.e., Academy of Management Review (AMR), Academy of Management Journal (AMJ), Academy of Management Perspectives (AMP) and Academy of Management Learning and Education (AMLE) - we see that these journals specifically exclude areas such as accounting, finance, and marketing from their range. In fact, the Academy of Management, the oldest and largest scholarly management association in the world, comprises as many as 24 divisions, but its definition of management is still significantly narrower compared to that which the Verband der Hochschullehrer für Betriebswirtschaft (German Academic Association for Business Research) is covering. Therefore, it is according to German scholarly traditions that $s b r$, its parent journal $z f b f$, and other leading German business journals, such as Zeitschrift für Betriebswirtschaft (zfb) and Die Betriebswirtschaft $(D B W)$, are all more broadly defined in their approach to management than is their U.S. competition or other English language journals. The advantage of such a model could be seen in integrating the various areas of business studies to a higher degree, thus increasing inter-area knowledge flow and circumventing silo thinking.

Another characteristic of traditional German business research and its leading journals is a comparatively stronger focus on more theoretical and system-or model-building contributions. Again, this focus contrasts to a certain degree with the more empirical research traditions of English-speaking origin which is globally dominating. sbr provides an excellent case in point here as well. 
A final distinction we are making is that German business studies and their leading journals tend to be centred on functional areas such as those already cited that $s b r$ is covering: accounting, finance, marketing, and organization studies. What features less prominently in German business studies are cross-functional, overarching or integrative subject areas, such as strategy, international business, cross-cultural management, change management or business ethics, to list just a few. In particular, the less-prominent role of strategy might be regarded as particularly remarkable by foreign observers. In non-German management studies, strategy is not just seen as one out of several subdisciplines of management, but as the most important one. While finance covers all matters for which the chief financial officer (CFO) is ultimately responsible, marketing everything the chief marketing office (CMO) is responsible for etc., strategy brings all these areas together and studies everything that lies within the responsibility of the CEO. To illustrate this point, one of the world's most famous business schools, Harvard, teaches its entire MBA programme from a strategic point of view, i.e., finance or marketing is taught from the strategic perspective of the $\mathrm{CEO}$, not from the more functional perspective of the $\mathrm{CFO}$ or the $\mathrm{CMO}$.

At least from an outside perspective we might therefore argue that traditional German business studies generally encompass a wider field than do the non-German management studies; yet, at their very heart lies a surprising gap, and that is strategy. What might be considered as the best of both worlds could be a combination of the wider, more integrative perspective of German business studies and the incorporation of crossfunctional areas, such as strategy, that characterize management studies outside Germany. By focusing on strategy, this special issue covers, in an exemplary fashion, some aspects of what would be considered part of the most important subdiscipline of management research in the globally dominating English speaking academic tradition, but tends to be less valued in the German academic tradition.

If we were to take a look at key developments that the subdiscipline of strategy has undergone in the last three decades, we might highlight the following three: first, with the advent of globalization, the focus of strategy has clearly become more global. Courses in non-German business schools that were previously labelled as Strategy have often been relabelled as Global Strategy and text books titled, for example, Global Strategic Management (e.g., Peng (2009)) have become some of the most frequently used text books in business schools. This development has been accompanied by the development of international business as a further subdiscipline of management studies.

The second key development of strategy is its emancipation from economics and its stronger focus on aspects previously covered only by more behavioural-oriented disciplines. This development leads us to probably the most significant fault line dividing management studies. One camp follows the paradigm of economics with mathematics as a reference point; the other camp adheres more to the paradigm of behavioural studies. Hedlund (1986), Doz and Prahalad (1987), and particularly Bartlett and Ghoshal (1989), and later Ghemawat (2007) are all examples of strategy authors who were by pedigree more economics-oriented, but who subsequently came to believe that the human factor plays the single most critical factor for the models they developed and for which they became famous. 
The third development of strategy we wish to highlight here results, to some degree, from the previous two: the growing understanding that context matters. Management does not take place in a vacuum, determined only by economical logic, but in a specific institutional and cultural environment that differs across national boundaries. Recognizing the importance of the cultural environment has led to the emergence of crosscultural management as a further subdiscipline of management studies. Over the last decade, cross-cultural management has firmly established itself in management studies; only a few business schools are left that do not offer such a course to their students.

While we support the emergence of cross-cultural management as a new and highly relevant subject area, we deplore the fact that the dialogue between international strategy and cross-cultural management is not as productive as it might be. As we discussed in the preface of our last special issue in the Scandinavian Journal of Management (Piekkari, Reiche, Pudelko and Carr (2010)), the development of new subject areas with own journals (e.g., Strategic Management Journal on one side and International Journal of Cross Cultural Management on the other) frequently leads to silo thinking and a lack of communication even across closely related subdisciplines. We continued to argue in our preface from 2010 that international strategy researchers would gain from the context-specific knowledge that cross-cultural management scholars have, which prevents international strategy researchers from over-generalizing. In contrast, cross-cultural researchers would benefit from more closely considering the organizational implications of their findings. As we have explored elsewhere (Pudelko, Carr and Henley (2006) and Pudelko, Carr, Fink and Wentges (2006)), integrating both research streams would also help to overcome the divide between the convergence tendencies of international strategy research and the predisposition towards divergence that characterizes much of the cross-cultural management literature.

It is the purpose of our EIASM workshop series in International Strategy and Cross-Cultural Management to bring together scholars from these two fields, encourage a fruitful dialogue, make efforts to integrate the debates of both disciplines and publish selected contributions in special issues such as this one. We are grateful to our many contributors over the last eight years, among them eminent scholars such as Julian Birkinshaw, Mary Yoko Brannen, Paula Caligiuri, Mark Mendenhall, Alan Rugman, Rosalie Tung and, in this special issue, Pervez Ghauri, all of whom have served as keynote speakers and authors in our publications.

Our special issue in 2010 was focused more on cross-cultural management. The current issue brings together more papers from international strategy. In addition to our ongoing objective of contributing to the integration of both subject areas, we hope that this special issue makes a contribution to more deeply embedding both international strategy and cross-cultural management in the German academic context. 
Our first two contributions, those by Ghauri, Elg, Tarnovskaya and Wang and by Ates and Prange, share more than one similarity. Both are conceptual in nature. Both can be positioned at the crossroads between international marketing and international strategy. Both start out with arguably the most important debate on the international strategy of MNCs: how to overcome the contradiction between global integration and local responsiveness. The authors we have cited above - Hedlund (1986), Doz and Prahalad (1987), Bartlett and Ghoshal (1989) and Ghemawat (2007) - all owe their fame to their respective contributions to this key debate. And ultimately, both Ghauri et al. and Ates and Prange refer to concepts from the marketing literature to address the integration-responsiveness debate in international strategy. We argued earlier that international strategists tend to focus on the integration argument, while scholars in cross-cultural management put the spotlight more on local responsiveness. Although Ghauri et al. and Ates and Prange do not come from the cross-cultural management angle (with the focus on employees), their marketing perspective (with the focus on customers) takes a similar position: highlighting the relevance of human behaviour and the impact the national context can have on human behaviour, both of which factors provide major challenges to global integration efforts.

In their contribution, Ghauri et al. focus on the market-driving strategy, which suggests that successful MNCs should base their operations on influencing and changing the market conditions and the minds of the customers rather than on adapting their own strategic approach and market activities. This strategy appears to be closely aligned with the resource-based view, a perspective particularly close to strategists who strive for global integration around core competencies. The important and highly relevant contributions Ghauri et al. make in their paper are twofold: first, to tease out certain organizational skills and capabilities that are required for the highly demanding market-driving strategy, specifically, the learning, branding, configuration, and networking capabilities. Second, to develop a framework that links these capabilities to market-driving activities intended to create changes in the target market, which can in turn lead to competitive advantage.

Ates and Prange's starting point is the "AAA triangle" developed by Ghemawat (2007), in which AAA stands for adaptation (or local responsiveness), aggregation (or global integration), and arbitrage (exploiting differences). Similar to the market-driving strategy discussed above, Ghemawat's framework addresses the difficulties that have been linked to the still leading paradigm of the transnational corporation, as developed by Bartlett and Ghoshal (1989). Ates and Prange agree with Ghemawat's conceptualization, but they argue as do many other authors, that Ghemawat has ignored the role of individual-level drivers. Consequently, they contribute to the strengthening of the microfoundations of strategy (see, e.g., Felin and Foss (2005)), i.e., the links between the macro-level of the firm and the individual level. These efforts closely mirror the objective of our workshop series in integrating the different levels of analysis (Piekkari et al. (2010); Reiche, Carr and Pudelko (2010)). To highlight the influence of the individual level on international strategy formulation, Ates and Prange focus particularly on the role of the individual customer. In doing so, they complement Ghemawat's AAA triangle with three levels of customer participation - customization, co-creation and co-for- 
mation - arriving at a conceptually highly interesting combined framework of AAACCC strategies.

The third contribution, which is by Fisch and Zschoche, addresses a core issue in the international strategy literature, the relation between a firm's level of multinationality, measured as the spread of a firm's foreign direct investment, and the performance of its international business. It is increasingly common to view the relation between multinationality and performance as S-shaped (e.g., Lu and Beamish (2004)). This literature usually builds on transaction-cost arguments to conceptualize the liabilities of foreignness and economies of scale as the main determinants of the S-shaped relation. In their empirical study, Fisch and Zschoche develop and test a refined theoretical basis to explain the shape of the relation. Drawing from information-cost theory (Casson (1999)) Fisch and Zschoche build a model that substantiates the S-shaped relation that is based on the total costs of international market intermediation external to the firm, and its internal costs of communication and coordination. They argue that these costs, rather than liabilities of foreignness and economies of scale, are specific to the level of multinationality and would therefore serve as a better predictor. In line with this argument, Fisch and Zschoche also conceptualize the liabilities of foreignness and economies of scale as having direct effects on a firm's performance of its international business that are independent from the $S$-shaped effect of multinationality. Drawing on a panel data set of 3,122 German firms over the course of four years, the authors find support for their hypotheses.

The paper by Krühler and Pidun relates to the Fisch and Zschoche study by also examining strategic investment decisions in multinationals. However, rather than looking at the geographical allocation of foreign direct investment, Krühler and Pidun address the question of which business units should reasonably be owned by the focal multinational, an issue discussed under the label of "parenting advantage" in the international strategy literature (Campbell et al., 1995). Krühler and Pidun note that the concept has received only scant attention in research thus far, making it difficult to draw meaningful conclusions concerning its application in corporate practice. To address this gap in the literature, Krühler and Pidun conducted an exploratory study among a global sample of 151 multi-business firms. Their goal was to assess the concept's practical relevance for corporate strategy, identify different types of parenting approaches, explore the concept's relevance for and operationalization in portfolio analysis, and particularly study the role of portfolio structure and cultural differences for the choice of parenting approaches. Although their sample was limited to Continental European, UK, and U.S. firms, Krühler and Pidun find relevant cultural differences in the preferred choice among the five distinct parenting approaches the study derived. This result provides a case in point for how the international strategy and cross-cultural management domains may be further integrated to benefit from each other.

The contribution by Hajro and Mandal stands at the cross-roads of international strategy and cross-cultural management. This study interlinks the macro and micro levels of analysis by studying individual-level outcomes in a research context that has received more attention by macro-level scholars: cross-border mergers and acquisitions (M\&As). 
Drawing from a longitudinal case study that outlines the unsuccessful integrative efforts between a German multinational and an Austrian service provider, the authors develop a narrative of the integrative process over time. Hajro and Mandal first identify the key constructs inherent in the integration process, which they derived from 46 interviews with staff from both organizations and participant observation. The authors then develop cause-andeffect relationships between these constructs. By doing so, they are able to trace the integration dynamics and highlight how specific managerial actions and the resulting reactions among staff can become self-reinforcing. For example, the pressure that managers exert on employees from the acquired firm to conform to the norms of the acquirer creates negative emotional reactions among the employees, which in turn leads managers to increase their pressure. Hajro and Mandal also show how perceptions of an organizational culture can change over time, for example, as employees from the acquired firm translate their resistance into a renewed awareness and appreciation of their former organizational identity, which may further complicate integration. Using this process narrative, the authors are able to study the dynamic interrelations among relevant variables, rather than using them as independent variables as previous research has mostly done (Teerikangas and Very (2006)). The study also provides an example of how micro and macro research, and by extension cross-cultural management and international strategy research, can be combined.

Pudelko and Tenzer's contribution is more a part of the cross-cultural management stream than of international strategy. By investigating if more cultural or institutional factors are the root cause of conflicts that occur in the foreign subsidiaries of MNCs, Pudelko and Tenzer's paper brings together two related research camps: cross-cultural management and institutional research. Both streams highlight the importance of contextual differences, and both are sceptical of the applicability of globally integrated management strategies. However, while cross-cultural management scholars often hold values and norms between home and host country accountable for the increased level of conflict in foreign subsidiaries, institutionalists emphasize the conflict potential of differences on the regulatory level, such as the political, legal and educational systems; capital markets, industrial relations, and corporate governance systems. Pudelko and Tenzer's empirical study, which is based on data from 617 foreign subsidiaries, suggests that both kinds of contextual factors, both cultural and institutional, must be considered and that neither one should be neglected in favour of the other. Furthermore, they suggest that culture might be a more encompassing concept than institutions.

We hope that readers of this special issue find the selected contributions interesting. We would be particularly delighted if they were to take this special issue as an incentive to contribute their research to future EIASM Workshops in International Strategy and Cross-Cultural Management.

MARKUS PUDELKO

Tübingen University, Germany

B. SEBASTIAN REICHE

IESE Business School, Spain
CHRIS CARR

University of Edinburgh Business School, UK

Special Issue Editors 


\section{References}

Bartlett, Christopher A. and Sumantra Ghoshal (1989), Managing Across Borders: The Transnational Solution, Boston, MA: Harvard Business School Press.

Campbell, Andrew, Michael Goold, and Marcus Alexander (1995), Corporate Strategy: The Quest for Parenting Advantage, Harvard Business Review 2, 120-132.

Casson, Mark (1999), The Organisation and Evolution of the Multinational Enterprise: An Information Cost Approach, Management International Review 39(1), 77-121.

Doz, Yves and Coimbatore K. Prahalad (1987), The Multinational Mission: Balancing Local Demands and Global Vision, New York: The Free Press.

Felin, Teppo and Nicolai Foss (2005), Strategic Organization: A Field in Search of Microfoundations, Strategic Organization 3(4), 441-455.

Ghemawat, Pankaj (2007), Managing Differences: The Central Challenges of Global Strategy, Harvard Business Review 85(3), 59-68.

Lu, Jane W. and Paul W. Beamish (2001), The Internationalization and Performance of SMEs, Strategic Management Journal 22(6/7), 565-586.

Peng, Mike (2009), Global Strategic Management, $2^{\text {nd }}$ ed., Florence, KY: Cengage Learning.

Piekkari, Rebecca, B. Sebastian Reiche, Markus Pudelko, and Chris Carr (2010), A Meeting of Minds? Insights from Intersections between International Strategy and Cross-Cultural Management Research, Scandinavian Management Journal 26 (3), 233-235.

Pudelko, Markus, Chris Carr, and John Henley (2006), Globalization and its Effects on International Strategy and Cross-Cultural Management, International Studies of Management \& Organization 36 (3), 3-8.

Pudelko, Markus, Chris Carr, Gerhard Fink, and Paul Wentges (2006), The Convergence Concept in Cross-Cultural Management Research, International Journal of Cross-Cultural Management 6(2), 15-18.

Reiche, B. Sebastian, Chris Carr, and Markus Pudelko (2010), The Role of Culture at Different Levels of Analysis, International Journal of Cross-Cultural Management 10 (2), 131-136.

Teerikangas, Satu and Philippe Very (2006), The Culture-Performance Relationship in M\&A: From Yes/No to How, British Journal of Management 17(1), 31-48. 